\title{
R\&D TAHAP ASSESMENT: KEEFEKTIFAN BAHAN AJAR STATISTIK PENDIDIKAN BERBASIS LC 5E BERBANTU MINITAB
}

\author{
Agus Abdillah $^{1 *)}$, Hendro Prasetyono ${ }^{2}$, Nur Rizkiyah ${ }^{3}$, Dona Fitria ${ }^{4}$, Burhanudin $^{5}$ \\ Universitas Indraprasta PGRI, Jakarta, Indonesia ${ }^{1-5}$ \\ Abdillahagus518@gmail.com ${ }^{1}$, hendro_prasetyono@unindra.ac.id ${ }^{2}$, qytaman@yahoo.com³ \\ fitriaqinthar@gmail.com ${ }^{4}$, hanzqinthar@gmail.com ${ }^{5}$
}

\begin{abstract}
$\begin{array}{ll} & \text { Abstract } \\ \text { Received: } 08 \text { Agustus } 2021 & \text { One indicator that learning can be said to be effective is optimal learning }\end{array}$ Revised: 18 September 2021 outcomes. In fact, to achieve the word "effective" is still far from Accepted: 28 September 2021 expectations. These problems cannot be separated from how the lecturers should apply appropriate learning models. This research is the R\&D stage of testing the effectiveness of teaching materials using a non-equivalent control group design. The population of all students of the Economic Education Study Program, Indraprasta PGRI University Semester V of the 2020/2021 academic year consists of 31 classes with 1175 students. The sample taken is class S5F (experiment class) as many as 42 people and Class S5E (control class) as many as 43 people. The analysis technique used is the independent t-test. The results of the descriptive analysis showed that the experiment class obtained an average value of learning outcomes that was higher than the control class $(80.61>74.02)$. While inductive analysis obtained t_statistic > t_table $(4.209>1.989)$. This means that there is a significant difference in learning outcomes between the experiment class and the control class. Therefore, it can be concluded that the Educational Statistics teaching material based LC 5E assisted by Minitab is very effective in its use in learning.

Keywords: Hasil Belajar, Learning Cycle, 5E, Minitab
\end{abstract}

(*) Corresponding Author: $\quad$ Abdillah, abdillahagus518@gmail.com, +62 81935672272

How to Cite: Abdillah, A., Prasetyono, H., Rizkiyah, N., Fitria, D., \& Burhanudin. (2021). R\&D Tahap Assesment: Keefektifan Bahan Ajar Statistik Pendidikan Berbasis LC 5E Berbantu Minitab. Research and Development Journal of Education, 7 (2), 493-503.

\section{INTRODUCTION}

Peningkatan mutu pendidikan di antaranya adalah model pembelajaran, sumber belajar, dan media pembelajaran yang dibutuhkan dalam proses pembelajaran. Sebagaimana temuan penelitian yang dilakukan oleh Abdillah (2017) menyatakan bahwa media pembelajaran berpengaruh positif dan signifikan. Selain dari media pembelajaran, pemberian penguatan (reinforcement) guru atau dosen juga sangatlah penting dalam meningkatkan kompetensi siswa atau hasil belajar siswa (Abdillah, A \& Hendro Prasetyono, 2019). Proses belajar mengajar hakekatnya adalah terjadinya interaksi antara dosen dengan mahasiswa. Kegiatan pembelajaran dirancang agar dapat memberikan pengalaman belajar yang melibatkan proses mental dan fisik melalui interaksi dalam rangka pencapaian kompetensi dasar. Pengalaman belajar yang dimaksud dapat terwujud melalui penggunaan model pembelajaran yang bervariasi dan berpusat pada mahasiswa. Melalui model pembelajaran, dosen dapat membantu mahasiswa mendapatkan informasi, ide, keterampilan, cara berpikir, dan mengekspresikan ide (Suprijono, 2012). Dosen seharusnya memikirkan bagaimana cara memilih model yang membuat mahasiswa dapat belajar secara optimal sesuai dengan kompetensi yang ingin dicapai sehingga pembelajaran dapat dikatakan efektif dan efisien. 
Faktanya, berdasarkan hasil wawancara kepada beberapa dosen pengampu mata kuliah Statistik Program Studi Pendidikan Ekonomi di Universitas Indraprasta PGRI dan Program Studi Pendidikan Luar Biasa di Universitas Negeri Jakarta, menyatakan bahwa materi yang begitu banyak dengan waktu yang relatif terbatas membuat dosen sulit mengajarkan konsep secara mendalam. Kemudian rendahnya pemahaman konsep yang dimiliki mahasiswa menyebabkan dosen harus mengajar ulang dan mengadakan remedial. Akibatnya, dosen kehabisan waktu dan masih banyak materi selanjutnya yang tidak dapat diajarkan secara maksimal. Salah satu materi yang menjadi permasalahan sebagian besar mahasiswa Semester 5 adalah materi korelasi dan regresi. Apalagi materi ini sangat diprioritaskan mahasiswa jenjang S1 sebagai bekal untuk melakukan penelitian nantinya. Dalam penelitian Prasetyono, et al. (2020) Penurunan hasil belajar mata kuliah Statistik dengan teknik analisis CHAID dipengaruhi oleh faktor motivasi belajar kelompok. Temuan tersebut sejalan dengan penelitian Abdillah, et al. (2020) bahwa kesulitan mahasiswa mengalami kesulitan belajar Statistik terutama pada materi korelasi dan regresi. Namun, kenyataannya hasil pre test sebelum penerapan bahan ajar Statistik berbasis model learning cycle 5E menunjukkan bahwa sebanyak $48 \%$ mahasiswa tidak mencapai Kriteria Kompetensi Minimal dengan nilai KKM pada materi ini adalah 70. Padahal saat kegiatan pembelajaran berlangsung, mahasiswa memperhatikan penjelasan dosen dengan baik. Hal ini diakibatkan oleh rendahnya pemahaman konsep karena mahasiswa hanya menghafalkan rumus tanpa memahami konsep.

Permasalahan tersebut tidak terlepas dari bagaiamana dosen seharusnya menerapkan model-model pembelajaran yang tepat. Oleh karena itu, perlu adanya pemilihan model pembelajaran yang cocok serta sumber belajar (bahan ajar) yang isi materinya komprehensif, tetapi mudah dipahami oleh mahasiswa. Dasar pertimbangan dalam memilih model pembelajaran adalah model pembelajaran yang diharapkan dapat membantu mahasiswa dalam meningkatkan penguasaan materi mata kuliah Statistik sehingga hasil belajar pun meningkat (Wena, 2012). Oleh karena itu, model yang dianggap tepat dengan dasar pertimbangan tersebut adalah model learning cycle 5E. Learning Cycle 5E merupakan rangkaian tahap-tahap kegiatan yang diorganisasi sedemikian rupa sehingga siswa dapat menguasai kompetensi-kompetensi yang harus dicapai dalam pembelajaran dengan jalan berperan aktif. Learning Cycle 5E terdiri atas lima fase yaitu (Bybee, at al, 2006); fase pembangkit minat (engagement), eksplorasi (exploration), penjelasan (explanation), elaborasi (elaboration/extention), dan evaluasi (Ergin, 2012).

Proses pembelajaran yang akan dilaksanakan menggunakan model pembelajaran learning cycle 5E berbantu software Minitab. Penggunaan Minitab dalam pembelajaran dimaksudkan agar pembelajaran dapat berlangsung secara efektif dan efisien. Hasil olahan data dengan Minitab tersebut nantinya dicocokkan dengan hasil olahan data secara manual. Selanjutkan mahasiswa dapat mengetahui tingkat keakuratan hasil olahan data (output) Minitab. Dengan demikian, terjadi diskusi kelompok dalam proses pembelajaran sehingga setiap mahasiswa diharapkan menguasai konten materi secara mendalam dan komprehensif.

Hasil-hasil penelitian sebelumnya yang relevan dengan penelitian ini antara lain; (Fadirubun dan Andriani, 2013), dan (Winarno, et al, 2015) menunjukkan bahwa model pembelajaran Learning Cycle 5E sangat efektif dalam meningkatkan hasil belajar siswa. Selain itu, hasil belajar akan mengalami peningkatan apabila didukung oleh efektivitas penggunaan media pembelajaran (Abdillah, 2017), Model pembelajaran kooperatif tipe group investigation dan numbered head together (Vhalery, 2019), dan model pembelajaran kooperatif tipe gallery walk dengan tipe learning together (Vhalery, 2019) serta perlunya reinforcement guru (Prasetyono et al., 2018). Namun perlu diketahui bahwa penelitian-penelitian sebelumnya terbatas pada penerapan model, yakni model 
learning cycle 5E terhadap hasil belajar. Berbeda dengan penelitian yang penulis lakukan. Penelitian ini mengkolaborasikan penerapan model, penggunaan sumber belajar (Bahan ajar) serta teknologi pembelajaran pendukung yang digunakan yang relevan dengan matakuliah. Sehingga hasil penelitian ini nantinya dapat menjadi rujukan karena memiliki kebaruan dari hasil-hasil penelitian sebelumnya.

Tujuan penelitian ini adalah untuk mengetahui dan menganalisis perbedaan antara hasil belajar mata kuliah Statistik menggunakan bahan ajar Statistik Pendidikan berbasis Learning Cycle 5E berbantuan Minitab dengan hasil belajar mata kuliah Statistik tanpa menggunakan bahan ajar Statistik Pendidikan berbasis Learning Cycle 5E berbantuan Minitab (Konvensional).

\section{METHODS}

\section{Desain Penelitian}

Research and Development untuk tahap assessment (Plompt, 2007) yakni tahap uji coba keefektivan bahan ajar Statistik berbasis LC 5E berbantuan Minitab ini menggunakan penelitian kuasi eksperimen. Menurut Sugiono (2015) Kuasi eksperimen digunakan karena kelompok kontrol tidak dapat berfungsi sepenuhnya untuk mengontrol variabel-variabel luar yang mempengaruhi penelitian eksperimen. Desain penelitian yang akan digunakan, yaitu Non equivalent Control Group Design, dimana dalam desain ini kelompok eksperimen maupun kelompok kontrol tidak dipilih secara random. Desain ini membandingkan kelompok eksperimen dan kelompok kontrol.

\section{Populasi dan Sampel}

Populasi dalam penelitian ini adalah mahasiswa Program Studi Pendidikan Ekonomi, Universitas Indraprasta PGRI Semester V (lima) tahun ajaran 2020/2021 yang terdiri dari 31 kelas dengan total mahasiswa sebanyak 1175 orang. Sampel yang diambil adalah Kelas S5F (kelas eksperimen) sebanyak 42 orang dan Kelas S5E (kelas kontrol) sebanyak 43 orang.

Instrumen yang digunakan dalam penelitian tahap assessment ini, yakni uji keefektivan bahan ajar berupa lembar soal atau lembar tes (Arikunto, 2015). Sebelum instrument tersebut digunakan, peneliti melakukan validasi terlebih dahulu. Sebelum dilakukan perhitungan independent $\mathrm{t}$ - test dilakukan uji normalitas. Analisis data menggunakan analisis data deskriptif dan analisis data inferensial.

\section{Teknik Analisis Data}

Efektifitas bahan ajar yang dikembangkan ditentukan dari perbedaan rata-rata posttest di kelas eksperimen dan rata-rata posttest di kelas kontrol (Purwanto, 2010). Data yang diperoleh dari hasil tes berjenis interval, maka sebelum menentukan tes untuk menentukan signifikasi perbedaan, distribusi data harus di uji homogenitas dan normalitasnya. Uji homogenitas yang dipakai peneliti adalah uji homogenitas dengan variansi terbesar dibanding variansi terkecil. Uji normalitas yang dipakai peneliti adalah uji Kolmogorov-Smirnov. Ada pun teknik yang digunakan adalah uji-t (independent ttest) untuk mengetahui ada atau tidaknya perbedaan yang signifikan (meyakinkan) dari dua buah mean sampel dari dua variabel yang dikomparatifkan. 


\section{RESULTS \& DISCUSSION}

\section{Results}

\section{Analisis Deskriptif Hasil Belajar}

Berdasarkan analisis deskriptif hasil belajar (posttest) pada kelas eksperimen yang diikuti oleh 42 mahasiswa, diperoleh nilai rata-rata ujian (mean) sebesar 80,62. Median sebesar 80 dan modus sebesar 85. Standar deviasi untuk kelas ekperimen sebesar 7,2. Sementara koefisien variansinya sebesar 8,9. Berikut disajikan grafik distribusi frekuensi hasil belajar kelas eksperimen:

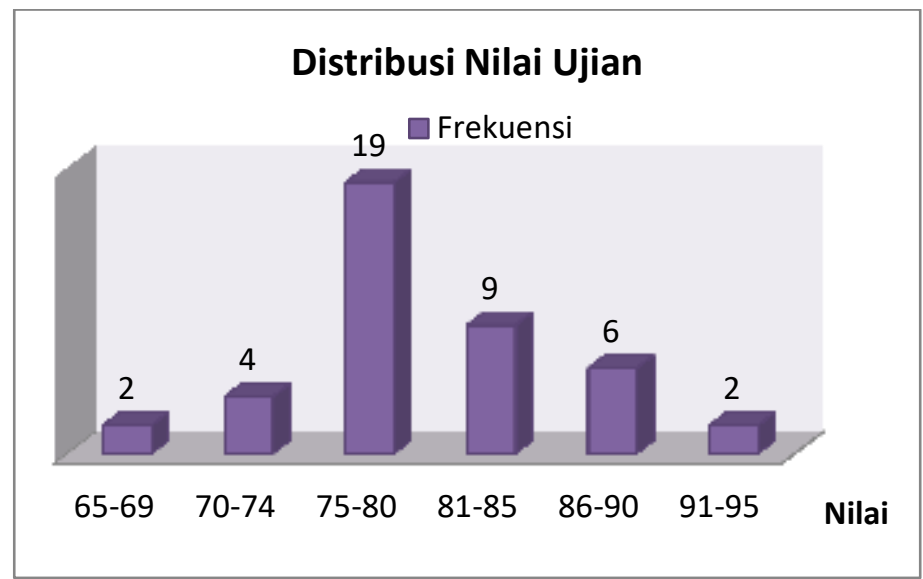

Gambar 1.

Distribusi Hasil Belajar Kelas Eksperimen Sumber: Olahan Data (2021)

Sedangkan analisis deskriptif hasil belajar (posttest) pada kelas kontrol yang diikuti oleh 43 mahasiswa, diperoleh nilai rata-rata ujian (mean) sebesar 74,02. Median sebesar 75 dan modus sebesar 75. Standar deviasi untuk kelas kontrol sebesar 7,3. Sementara koefisien variansinya sebesar 9,8. Berikut disajikan grafik distribusi frekuensi hasil belajar kelas kontrol:

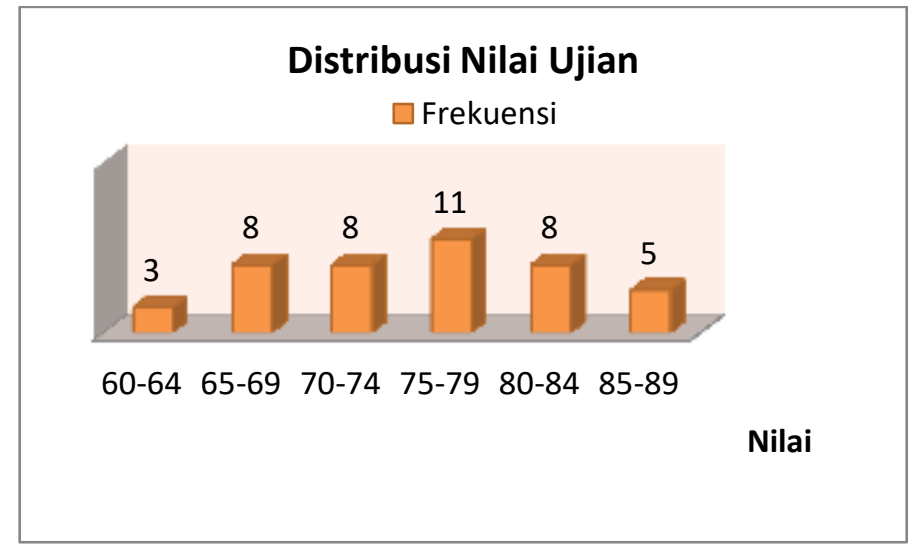

Gambar 2.

Distribusi Hasil Belajar Kelas Kontrol

Sumber: Olahan Data (2021) 
Selanjutnya dapat kita lihat perbandingan hasil belajar Statistik mahasiswa berdasarkan perhitungan statistik deskriptif baik mahasiswa kelas eksperimen dan kelas kontrol di atas, secara ringkas dapat dilihat pada tabel 1 berikut:

Tabel 1.

Distribusi Frekuensi Perbandingan Perkembangan Hasil Belajar Kelas Eksperimen dan Kontrol

\begin{tabular}{|c|c|c|c|c|c|}
\hline \multirow{2}{*}{ Interval } & \multicolumn{2}{|c|}{ Kelas Eksperimen } & \multirow{2}{*}{ Interval } & \multicolumn{2}{|c|}{ Kelas Kontrol } \\
\hline & $\mathrm{Fi}$ & $\%$ & & $\mathrm{Fi}$ & $\%$ \\
\hline $65-69$ & 2 & 4,76 & $60-64$ & 3 & 6,98 \\
\hline $70-74$ & 4 & 9,52 & $65-69$ & 8 & 18,60 \\
\hline $75-80$ & 19 & 45,24 & $70-74$ & 8 & 18,60 \\
\hline $81-85$ & 9 & 21,43 & $75-79$ & 11 & 25,59 \\
\hline $86-90$ & 6 & 14,29 & $80-84$ & 8 & 18,60 \\
\hline $91-95$ & 2 & 4,76 & $85-89$ & 5 & 11,63 \\
\hline Total & 42 & 100 & & 43 & 100 \\
\hline Mean & & 80,61 & & & 74,02 \\
\hline Median & & 80 & & & 75 \\
\hline Mode & & 85 & & & 75 \\
\hline $\operatorname{Max}$ & & 95 & & & 88 \\
\hline Min & & 65 & & & 62 \\
\hline Std.Deviation & & 7,16 & & & 7,28 \\
\hline $\begin{array}{l}\text { Coef. Of } \\
\text { Variance }\end{array}$ & & 8,88 & & & 9,84 \\
\hline
\end{tabular}

Sumber: Olahan Data (2021)

Berdasarkan tabel di atas dapat dilihat bahwa hasil belajar mahasiswa yang diajarkan dengan menggunakan Bahan ajar Statistik berbasis LC $5 E$ berbantuan Minitab 17.2.1 memperoleh hasil belajar yang lebih tinggi jika dibandingkan dengan hasil belajar mahasiswa yang diajarkan tanpa menggunakan Bahan ajar Statistik berbasis $L C$ $5 E$ berbantuan Minitab 17.2.1. Rata-rata hasil belajar yang diperoleh mahasiswa pada kelas eksperimen adalah sebesar 80,61 dengan nilai tertinggi yang diperoleh mahasiswa adalah 95 dan nilai terendah adalah 65 , dengan frekuensi nilai yang sering muncul adalah 85. Sedangkan rata-rata hasil belajar yang diperoleh mahasiswa pada kelas kontrol adalah sebesar 74,02 dengan nilai tertinggi 88 dan nilai terendah adalah 62, dengan frekuensi nilai yang sering muncul adalah 75 .

\section{Analisis Induktif Hasil Belajar}

\section{Uji Normalitas}

Uji normalitas ini bertujuan untuk mengetahui apakah kelompok sampel berasal dari populasi yang berdistribusi normal atau tidak. Artinya uji normaliatas ini berguna untuk melihat data yang normal, kalau data tidak normal maka akan memberikan kesimpulan yang salah nantinya. Uji yang digunakan adalah uji Kolmogorov-Smirnov. Berikut data hasil uji normalitas terlihat pada tabel berikut: 
Tabel 2.

Hasil Uji Normalitas

\begin{tabular}{lcccc}
\hline & $\begin{array}{c}\text { Kelas } \\
\text { Eksperimen } \\
\text { (Pre test) }\end{array}$ & $\begin{array}{c}\text { Kelas Kontrol } \\
\text { (Pre test) }\end{array}$ & $\begin{array}{c}\text { Kelas } \\
\text { Eksperimen } \\
\text { (Post test) }\end{array}$ & $\begin{array}{c}\text { Kelas Kontrol } \\
\text { (Post test) }\end{array}$ \\
\hline $\mathrm{n}$ & 42 & 43 & 42 & 43 \\
Mean & 69,38 & 66,23 & 80,61 & 74,02 \\
Std. Deviation & 7,26 & 7,20 & 7,16 & 7,28 \\
Test Statistic & 0,133 & 0,106 & 0,134 & 0,128 \\
Asymp. Sig. (2-tailed) & 0,060 & 0,200 & 0,054 & 0,073 \\
\hline
\end{tabular}

Sumber: Olahan Data (2021)

Berdasarkan tabel di atas terlihat bahwa pada kelas eksperimen hasil belajar pretest dan posttest diperoleh Sig. sebesar 0,06 dan 0,054 lebih besar dari $\alpha=0,05$ (Sig. $>\alpha$ ). Sedangkan pada kelas kontrol pretest dan posttest diperoleh Sig. sebesar 0,200 dan 0,073 lebih besar dari $\alpha=0,05$ (Sig. $>\alpha$ ). Jadi dapat disimpulkan bahwa data untuk hasil belajar mahasiswa baik kelas eksperimen maupun kelas kontrol berdistribusi normal.

\section{Uji Homogenitas}

Uji homogenitas dilakukan untuk mengetahui apakah data penelitian berasal dari populasi yang homogen. Dengan menggunakan test of homogenity of variance. diperoleh hasil uji homogenitas sebagai berikut:

Tabel 3.

Hasil Uji Homogenitas

\begin{tabular}{llcrrr}
\hline & & $\begin{array}{c}\text { Levene } \\
\text { Statistic }\end{array}$ & df 1 & df 2 & Sig \\
\hline Hasil Belajar (Pretest) & Based on Mean & 0,000 & 1 & 83 & 0,994 \\
& $\begin{array}{l}\text { Based on Median } \\
\text { Based on Median and }\end{array}$ & 0,000 & 1 & 83 & 0,994 \\
& with adjusted df & 0,000 & 1 & 82,83 & 0,994 \\
& Based on trimmed mean & 0,000 & 1 & 83 & 0,986 \\
\multirow{2}{*}{$\begin{array}{l}\text { Hasil Belajar } \\
\text { Posttest) }\end{array}$} & Based on Mean & 0,070 & 1 & 83 & 0,792 \\
& Based on Median & 0.065 & 1 & 83 & 0,800 \\
& $\begin{array}{l}\text { Based on Median and } \\
\text { with adjusted df }\end{array}$ & 0,065 & 1 & 82,98 & 0,800 \\
& Based on trimmed mean & 0,071 & 1 & 83 & 0,791 \\
\hline
\end{tabular}

Sumber: Olahan Data (2021)

Berdasarkan hasil perhitungan di atas, diperoleh data pretest dan data posttest mempunyai nilai signifikansi Based on Mean masing-masing 0,994 dan 0,792 lebih besar dari 0,05 maka dapat disimpulkan bahwa variance pre test dan post test baik kelas eksperimen maupun kelas kontrol adalah sama atau homogen. Dengan demikian salah satu syarat dari uji independent t-test telah terpenuhi. 


\section{Pengujian hipotesis}

Setelah uji normalitas dan homogenitas terpenuhi maka langkah selanjutnya peneliti dapat melanjutkan tahap pengujian hipotesis untuk mengetahui apakah hipotesis yang diajukan diterima atau ditolak. Dalam pengujian hipotesis ini, kriteria untuk menolak $H_{0}$ atau menerima $H_{a}$ berdasarkan pada Significance (yang disingkat Sig.). Jika Sig. $<\alpha$ maka $H_{0}$ ditolak atau $H_{a}$ diterima dan sebaliknya jika Sig. $>\alpha$ maka $H_{0}$ diterima dan $H_{a}$ ditolak. Teknik statistik yang digunakan adalah teknik $t$-test untuk menguji hipotesis yang menyatakan adanya perbedaan rata-rata hasil belajar mahasiswa yang pembelajarannya menggunakan Bahan ajar Statistik berbasis $L C 5 E$ berbantu Minitab dengan hasil belajar mahasiswa yang tanpa menggunakan Bahan ajar Statistik berbasis $L C 5 E$ berbantu Minitab (konvensional). Adapun perhitungan hipotesis $t$-test diganti dengan $Z$-test. Karena masing-masing kelompok sampel sebanyak 42 dan $43(\mathrm{n}>30)$. Rumus $t$-test $\left(t_{\text {hitung }}\right)$ maupun $Z$-test $\left(Z_{\text {hitung }}\right)$ pada hakikatnya sama. Uji t digunakan untuk sampel berukuran kecil $(\mathrm{n}<30)$. Sedangkan uji $\mathrm{Z}$ digunakan untuk sampel besar $(\mathrm{n} \geq 30)$. Hasil uji statistik dapat dilihat pada tabel berikut:

Tabel 4.

Independent Samples t-test

\begin{tabular}{|c|c|c|c|c|c|c|c|c|c|c|}
\hline & & \multicolumn{2}{|c|}{$\begin{array}{l}\text { Levene's Test } \\
\text { for Equality of } \\
\text { Variances }\end{array}$} & \multirow[b]{2}{*}{$\mathbf{t}$} & \multirow[b]{2}{*}{ df } & \multicolumn{3}{|c|}{ t-test for Equality of Means } & \multicolumn{2}{|c|}{$\begin{array}{l}\text { 95\% Confidence } \\
\text { Interval of the } \\
\text { Difference }\end{array}$} \\
\hline & & $\mathbf{F}$ & Sig. & & & $\begin{array}{l}\text { Sig. (2- } \\
\text { tailed) }\end{array}$ & $\begin{array}{c}\text { Mean } \\
\text { Difference }\end{array}$ & $\begin{array}{l}\text { Std. Error } \\
\text { Difference }\end{array}$ & Lower & Upper \\
\hline $\begin{array}{l}\text { Hasil } \\
\text { Belajar } \\
\text { (Pre test) }\end{array}$ & $\begin{array}{l}\text { Equal } \\
\text { variances } \\
\text { assumed }\end{array}$ & 0,000 & 0,994 & 2,002 & 83 & 0,049 & 3,14839 & 1,57229 & 0,0211 & 6,275 \\
\hline \multirow{3}{*}{$\begin{array}{l}\text { Hasil } \\
\text { Belajar } \\
\text { (Post } \\
\text { test) }\end{array}$} & $\begin{array}{l}\text { Equal } \\
\text { variances } \\
\text { not } \\
\text { assumed }\end{array}$ & \multirow{3}{*}{0,070} & \multirow{3}{*}{0,792} & 2,002 & 82,89 & 0,049 & 3,14839 & 1,57254 & 0,0206 & 6,276 \\
\hline & $\begin{array}{l}\text { Equal } \\
\text { variances } \\
\text { assumed }\end{array}$ & & & 4,209 & 83 & 0,000 & 6,59579 & 1,56711 & 3,4788 & 9,713 \\
\hline & $\begin{array}{l}\text { Equal } \\
\text { variances } \\
\text { not } \\
\text { assumed }\end{array}$ & & & 4,210 & 82,99 & 0,000 & 6,59579 & 1,56679 & 3,4795 & 9,712 \\
\hline
\end{tabular}

Sumber: Olahan Data (2021)

Berdasarkan hasil perhitungan atau analisis hasil belajar post test kelas eksperimen dengan kelas kontrol seperti yang terdapat pada tabel 30 di atas, diperoleh $t_{\text {hitung }}>t_{\text {tabel }}(4,209>1,989)$ atau $Z_{\text {hitung }}>Z_{\text {tabel }}(4,209>1,645)$. Dengan demikian dapat diambil keputusan bahwa hipotesis $\left(H_{0}\right)$ ditolak dan $H_{a}$ diterima karena Sig. $<\alpha(0,000<0,05)$. Artinya terdapat perbedaan yang signifikan hasil belajar antara kelompok mahasiswa yang menggunakan Bahan ajar berbasis $L C 5 E$ berbantu Minitab dengan hasil belajar kelompok mahasiswa yang tidak (tanpa) menggunakan Bahan ajar Statistik berbasis LC 5E berbantu Minitab.

Selain itu, dengan menggunakan pengujian hipotesis untuk sampel berpasangan (paired sample t-test). Dalam hal ini khusus kelas eksperimen (hasil belajar sebelum dan sesudah menggunakan Bahan ajar Statistik berbasis LC $5 E$ berbantu Minitab) dapat diketahui pada tabel berikut: 
Tabel 5.

Paired Sample t-test

\begin{tabular}{|c|c|c|c|c|c|c|c|c|c|}
\hline & & & & ired Dif & $\begin{array}{r}\text { ences } \\
95 \% \mathrm{Co} \\
\text { Interv } \\
\text { Diffe }\end{array}$ & $\begin{array}{l}\text { fidence } \\
\text { of the } \\
\text { ence }\end{array}$ & & & \\
\hline & & Mean & $\begin{array}{c}\text { Std. } \\
\text { Deviation }\end{array}$ & $\begin{array}{l}\text { Error } \\
\text { Mean }\end{array}$ & Lower & Upper & $\mathbf{t}$ & df & $\begin{array}{l}\text { Sig. (2 } \\
\text { tailed) }\end{array}$ \\
\hline Pair 1 & $\begin{array}{l}\text { Sebelum } \\
\text { menggunakan } \\
\text { bahan ajar - } \\
\text { Sesudah } \\
\text { menggunakan } \\
\text { bahan ajar }\end{array}$ & $-11,238$ & 2,80947 & 0,43351 & $-12,113$ & $-10,363$ & $-25,92$ & 41 & 0,000 \\
\hline
\end{tabular}

Analisis hasil belajar pada kelompok mahasiswa sebelum dan sesudah menggunakan Bahan ajar Statistik berbasis LC 5E berbantuan Minitab 17.2.1 pada tabel 31 di atas, diperoleh $t_{\text {hitung }}>t_{\text {tabel }}(25,923>2,020)$ atau $Z_{\text {hitung }}>Z_{\text {tabel }}$ ( 25,923 > 1,645) Dengan demikian dapat diambil keputusan bahwa hipotesis $\left(H_{0}\right)$ ditolak dan $H_{a}$ diterima karena Sig. $<\alpha(0,000<0,05)$. Hal ini dapat disimpulkan bahwa terdapat perbedaan yang signifikan hasil belajar kelompok mahasiswa sebelum menggunakan bahan ajar Statistik berbasis $L C 5 E$ berbantuan Minitab 17.2.1 dengan sesudah menggunakan Bahan ajar Statistik berbasis LC $5 E$ berbantuan Minitab 17.2.

\section{Discussion}

Hasil belajar yang diperoleh kedua kelas dapat dilihat berdasarkan perbandingan nilai post-test. Terdapat perbedaan yang signifikan hasil belajar antara kelas eksperimen dengan kelas kontrol. Hasil belajar mahasiswa pada kelas eksperimen lebih tinggi dibandingkan hasil belajar mahasiswa pada kelas kontrol. Nilai rata-rata post-test mahasiswa pada kelas eksperimen sebesar 80,61 lebih tinggi dibandingkan nilai ratarata post-test pada kelas control 74,02. Kemudian analisis induktif diperoleh t hitung $>\mathrm{t}$ tabel $(4,209>1,989)$. Perbedaan hasil belajar mahasiswa pada kedua kelas ini disebabkan oleh perlakuan yang berbeda dalam proses pembelajaran di dua kelas tersebut. Kelas eksperimen menggunakan Bahan ajar Statistik Pendidikan yang sudah dikembangkan, serta menggunakan model pembelajaran Learning Cycle 5E berbantu Minitab. Sedangkan pada kelas kontrol tidak menggunakan Bahan ajar Statistik Pendidikan, serta model pembelajaran yang diterapkan adalah model konvensional dan tidak dibantu oleh teknologi (Software Minitab).

Temuan penelitian ini didukung oleh beberapa hasil penelitian yang sudah pernah dilakukan oleh (Fadirubun \& Yana Andriani, 2013; dan Asmawati, R. \& Wuryanto, 2014; Winarno, et al., 2015). Namun demikian, penelitian-penelitian tersebut terbatas pada penerapan model Learning Cycle 5E terhadap hasil belajar. Artinya bahwa penelitian yang penulis lakukan ini memiliki kebaruan berupa kolaborasi penerapan model, penggunaan sumber belajar (Bahan ajar) serta teknologi pembelajaran pendukung yang digunakan yang relevan dengan matakuliah. Sehingga hasil penelitian ini nantinya dapat menjadi rujukan karena memiliki kebaruan dari hasil-hasil penelitian sebelumnya. Selain itu, terdapat hasil penelitian yang nyaris sama mengenai efektivitas 
penggunaan model pembelajaran terhadap hasil belajar, akan tetapi model pembelajaran yang diterapkan tidak sama. Hanya saja model tersebut bersifat konstruktivisme sehingga menjadi rujukan pula dalam penelitian ini. Hasil-hasil penelitian tersebut dilakukan oleh (Hussain at al., 2019; Moule, 2007; Skalka \& Obonya, 2019; Odukoya et al., 2017; and Lee \& Kim, 2017).

Dengan demikian, berdasarkan hasil analisis deskriptif dan analisis induktif mengenai hasil belajar Statistik, maka dapat disimpulkan bahwa Bahan ajar Statistik Pendidikan berbasis LC 5E berbantuan Minitab sangat efektif untuk diterapkan atau efektif penggunaannya dalam pembelajaran. Rekomendasi tim peneliti yaitu bahwa Bahan ajar Statistik sangat layak untuk dicetak, digandakan, dipublikasikan atau disebarluaskan secara nasional.

\section{CONCLUSION}

Berdasarkan hasil penelitian dan pembahasan yang telah dipaparkan di atas, maka dapat diambil beberapa kesimpulan antara lain sebagai berikut:

1. Pada analisis deskriptif, hasil belajar mahasiswa yang diajarkan dengan menggunakan Bahan ajar Statistik berbasis $L C 5 E$ berbantu Minitab memperoleh hasil belajar yang lebih tinggi jika dibandingkan dengan hasil belajar mahasiswa yang diajarkan tanpa menggunakan Bahan ajar Statistik berbasis $L C 5 E$ berbantu Minitab. Hal ini dapat dilihat dari mean, median, dan modus hasil belajar antara mahasiswa pada kelas eksperimen dan mahasiswa pada kelas kontrol.

2. Terdapat perbedaan yang signifikan hasil belajar antara kelas eksperimen dengan kelas kontrol. Hasil belajar mahasiswa pada kelas eksperimen lebih tinggi dibandingkan hasil belajar mahasiswa pada kelas kontrol.

3. Tahap akhir dari pada Penelitian dan Pengembangan ini yakni tahap assessment, dimana telah dilaksanakan pengujian mengenai keefektivan bahan ajar Statistik Pendidikan berbasis LC 5E berbantu Minitab. Selanjutnya telah diketahui hasil analisis deskriptif dan analisis induktif, maka dapat disimpulkan bahwa Bahan ajar Statistik Pendidikan berbasis LC 5E berbantuan Minitab sangat efektif untuk diterapkan atau efektif penggunaannya dalam pembelajaran pada matakuliah Statistik. ini yaitu:

Adapun beberapa saran yang dapat peneliti berikan setelah melakukan penelitian

1. Kepada pihak dosen khususnya di Universitas Indraprasta PGRI agar mulai membiasakan diri untuk menggunakan model pembelajaran inovatif dan kreatif seperti model pembelajaran Learning Cycle 5E sehingga minat dan motivasi mahasiswa meningkat yang implikasinya pada peningkatan hasil belajar Statistik.

2. Penggunaan model pembelajaran Learning Cycle 5E berbantu Minitab membutuhkan banyak waktu. Oleh karena itu, dosen harus mampu membagi waktu atau mengalokasikan waktu dan materi yang hendak disampaikan secara tepat pada setiap pertemuan, sehingga proses pembelajaran dapat tercapai dengan optimal.

3. Kepada peneliti selanjutnya diharapkan menggunakan model pembelajaran Learning Cycle 5E. Namun, perlu mencoba software lainnya seperti SPSS, E-View, AMOS dan lain-lain yang mendukung proses belajar mahasiswa pada mata kuliah Statistik. Hal ini juga agar nantinya mahasiswa ketika hendak menyusun tugas akhir atau skripsi dapat mengolah data secara mandiri. 


\section{ACKNOWLEDGEMENT}

Penelitian dan penulisan artikel ini didanai oleh Kementerian Pendidikan dan Kebudayaan, Badan Riset dan Inovasi Nasional (Kemendikbud Brin) Kemristek DIPA: Direktorat Penelitian dan Pengabdian Kepada Masyarakat No: 25/E1/KPT/2020 dan Nomor Kontrak: 092/LL3/PG/2020 dengan skema "PKPT". Oleh karena itu, penulis mengucapkan terima kasih yang tak terhingga. Hal ini merupakan kebanggaan sekaligus sebuah kesempatan bagi penulis dalam mengembangkan kapasitas. Penulis juga mengucapkan terima kasih yang setulus-tulusnya kepada semua pihak yang telah membantu jalannya penelitian hingga artikel ini terbit.

\section{REFERENCES}

Abdillah, A. (2017). Efektivitas Media Pembelajaran dan Minat Belajar Pengaruhnya Terhadap Hasil Belajar Akuntansi Dengan Motivasi Belajar Sebagai Variabel Intervening Pada Siswa Kelas XI SMK Negeri dan Swasta Di Jakarta Timur. Jupeko (Jurnal Pendidikan Ekonomi). Vol. 1 No.2. pp. 11-25. ISSN: 2548-6187 https:// doi.org/10.29100/.v1i2.222

Abdillah, A., \& Prasetyono, H. (2019). Pengaruh Reinforcement Guru Terhadap Kompetensi Afektif Siswa Sma Jakarta Timur Dalam Meminimalisir Berita Hoax. Research and Development Journal of Education. Vol. 5 (1), 03-10. https://doi.org/10.30998/rdje.v5i1.3383

Abdillah, A., Sutisna, A., Tarjiah, I., Fitria, D., \& Widiyarto, T. (2020). Application of Multinomial Logistic Regression to analyze learning difficulties in statistics courses. Journal of Physics: Conference Series, 1490, 1-6. https://doi.org/10.1088/1742-6596/1490/1/012012.

Arikunto, Suharsimi. (2015). Dasar - Dasar Evaluasi Pendidikan. Jakarta: Bumi Aksara.

Asmawati, R., \& Wuryanto. (2014). Keefektifan Model Pembelajaran LC 5E Dan TSTS Berbantuan LKPD Terhadap Hasil Belajar. Jurnal Kreano, Vol. 5 (1) ISSN : 20862334. https://journal.unnes.ac.id/nju/index.php/kreano/article/viewFile/3274/3219

Bybee, R. W., Taylor, J. A., Gardner, A., Scotter, P.V., Powell, J. C., Westbrook, A., and Landes, N. (2006). The BSCS 5E Instructional Model: Origins and Effectiveness, Colorado: Mark Dabling Boulevard.

Dimyati dan Mudjiono. (2009). Belajar dan Pembelajaran. Jakarta: Rineka Cipta.

Ergin, I. (2012). Constructivist Approach Based 5E model and Usability Instructional Physics. Lat. Am. J. Phys. Educ. Vol. 6, No. 1, 14-20. ISSN 1870-9095. https://www.lajpe.org

Fadirubun, Yana Andriani. (2013). Keefektifan Pembelajaran Learning Cycle 5e Berbasis Inkuiri Pada Pencapaian Kemampuan Pemecahan Masalah Siswa SMP Pada Materi Segi Empat. Skripsi. Tidak dipublikasikan. Semarang: UNNES.

Hamalik, O. (2010). Proses Belajar mengajar. Jakarta: PT Bumi Aksara.

Hussain, S., Muhsin, Z. F., Salal, Y. K., Theodorou, P., Kurtoğlu, F., \& Hazarika, G. C. (2019). Prediction model on student performance based on internal assessment using deep learning. International Journal of Emerging Technologies in Learning, 14(8), 4-22. https:// doi.org/10.3991/ijet.v14i08.10001

Lee, J., Lim, C., \& Kim, H. (2017). Development of an instructional design model for flipped learning in higher education. Educational Technology Research and Development, 65(2), 427-453. https://doi.org/10.1007/s11423-016-9502-1.

Moule, P. (2007). Challenging the five-stage model for e-learning: a new approach. Alt-J, 15(1), 37-50. https://doi.org/10.1080/09687760601129588 
Odukoya, J. A., Adekeye, O., \& Okunlola, S. (2017). Assessing the Effectiveness of Mobile Learning Devices in Tertiary Institutions: The Experience of Undergraduates in a Nigerian Private University. International Journal of Interactive Mobile Technologies (IJIM), $11(4), \quad 160$. https://doi.org/10.3991/ijim.v11i4.6828.

Plomp, T. (2007). Educational Design Research : An Introduction, dalam An Introduction to Educational Research. Enschede, Netherland: National Institute for Curriculum Development.

Prasetyono, H., Abdillah, A., Anita T., Nurfarkhana A., \& Sefudin, A. (2020). Identification of the decline in learning outcomes in statistics courses using the chi squared automatic interaction detection method. Journal of Physics: Conference Series, 1490. 1-9. https://doi.org/10.1088/1742-6596/1490/1/012072.

Prasetyono, H., Abdillah, A., Widiarto, T., \& Sriyono, H. (2018). Character-based economic learning implementation and teacher's reinforcement on student's affective competence in minimizing hoax. Cakrawala Pendidikan, 37(3), 426-435. https://doi.org/10.21831/cp.v38i3.21583.

Purwanto, M. Ngalim. (2010). Prinsip-Prinsip dan Teknik Evaluasi Pengajaran. Bandung: Remaja Rosdakarya.

Skalka, J., Drlik, M., \& Obonya, J. (2019). Automated assessment in learning and teaching programming languages using virtual learning environment. IEEE Global Engineering Education Conference, EDUCON. https://doi.org/10.1109/EDUCON.2019.87251 27.

Sudjana, N. (2009). Penilaiaan Hasil Proses Belajar Mengajar. Bandung: PT Remaja Rosdakarya Offset.

Sugiyono. 2016. Metode Penelitian Pendidikan Pendekatan Kuantitatif, Kualitatif, dan R\&D. Bandung: Alfabeta.

Suprijono, Agus. (2012). Cooperative Learning : Teori \& Aplikasi Paikem. Yogyakarta: Pustaka Pelajar.

Vhalery, Rendika. (2019). Perbandingan Aktivitas Belajar Melalui Model Pembelajaran Kooperatif Tipe Group Investigation dan Numbered Head Together. Research and Development Journal Of Education. Vol. $6 \quad$ (1), 8093. http://dx.doi.org/10.30998/rdje.v6i1.4172.

Vhalery, Rendika. (2019). Perbandingan Model Pembelajaran Kooperatif Tipe Gallery walk dengan Tipe Learning together pada Aktivitas Belajar Peserta Didik di SMA Tri Dharma Palembang. Jurnal Inovasi Pendidikan Ekonomi (JIPE). Vol. 9 (1), 110. https://doi.org/10.24036/011044950.

Wena, Made. (2012). Strategi Pembelajaran Inovatif Kontemporer. Jakarta: PT Bumi Aksara.

Winarno, Muhammad, et al. (2015). Efektivitas Model Pembelajaran Learning Cycle Berbantuan Lembar Kegiatan Peserta Didik (LKPD) Pada Pokok Bahasan Logika Matematika Terhadap Hasil Belajar Kelas X SMA Negeri 1 Terisi - Indramayu. EduMa, 4 (2) : 75 - 87. https://doi.org/10.24235/eduma.v4i2.31. 